\title{
Concern and Attitudes Toward Zika Virus in Jarabacoa, Dominican Republic: A Cross-Sectional Study
}

\author{
Gregory Black ${ }^{1}$, Eric Hasenkamp ${ }^{1}$, Nicholas Johnson ${ }^{1}$, Rosanna Ianiro ${ }^{2}$, Ricardo Izurieta ${ }^{2} \&$ Miguel Reina Ortiz $^{2}$ \\ ${ }^{1}$ Morsani College of Medicine, University of South Florida, Tampa, Florida, USA \\ ${ }^{2}$ College of Public Health, University of South Florida, Tampa, Florida, USA \\ Correspondence: Miguel Reina Ortiz, College of Public Health, University of South Florida, Tampa, Florida. Tel: \\ 813-974-6253. E-mail: mreina@health.usf.edu
}

Received: September 10, 2018 Accepted: October 18, 2018 Online Published: November 5, 2018

doi:10.5539/gjhs.v10n12p1 URL: https://doi.org/10.5539/gjhs.v10n12p1

\begin{abstract}
Background and Objectives: The Zika virus, a member of the flavivirus genus, is an emerging threat to many tropical regions of the world. This study was designed to assess the level of knowledge, attitudes and concern in regards to the Zika virus in the community of Jarabacoa, Dominican Republic, with the hopes of guiding future efforts toward public education and prevention of future public health threats.
\end{abstract}

Methods: A cross-sectional survey was conducted in the rural communities of Jarabacoa during October 2016 and October 2017. Individuals completed a 14-point survey evaluating: level of concern towards Zika (1=no concern, $3=$ neutral, $5=$ extremely concerned), knowledge level of the disease, use of personal protection against the virus, how people initially heard about the disease and contraception use.

Results: Overall, women were more concerned than men about contracting the virus $(\mathrm{p}<.001, \mathrm{CI}-2.510,-0.826)$. Of the respondents $(\mathrm{N}=138), 66 \%$ learned about Zika from the $\mathrm{TV} /$ news and $24.6 \%$ from their medical provider. $5 \%$ knew Zika was contracted from blood and 2\% from pregnancy, and only $17 \%$ of respondents knew that it was contracted through sex. For protection from Zika, only $8 \%$ used condoms. Of the women trying to get pregnant, none knew Zika could be transmitted through sex.

Conclusion: This study revealed that women were more concerned about the Zika virus than men and that knowledge about the virus was limited. In general, people are protecting themselves against vector borne transmission but not non-vector borne modes of transmission such as sexual intercourse. Also, public health education is lacking. Further studies are needed with more male participants, focus on contraception and social media's effect on public health education.

Keywords: knowledge, attitudes, practice, Zika virus, Dominican Republic

\section{Introduction}

The Zika virus, a member of the flavivirus genus, is an emerging threat to many tropical regions of the world. It has been associated with flu-like symptoms, Guillain-Barre syndrome and microcephaly in newborns (CaoLormeau et al., 2016; Rasmussen, Jamieson, Honein, \& Petersen, 2016; Mlakar et al., 2016). Zika virus is unique in the fact that it is transmitted both through Aedes species mosquito vectors and sexually through bodily fluids as evidenced by D'Ortenzio et al. (2016) who found high viral loads of Zika virus in semen (Chouin-Carneiro et al., 2016). In addition, Zika has also been associated with early spontaneous abortion. One case study found Zika RNA in placental and fetal tissues by RT-PCR in a mother of 10.5 weeks gestation, further confirming the transplacental transfer of Zika virus (Goncé et al., 2018). In 2017, there were 966 suspected cases of Zika in pregnant women in the Dominican Republic alone (Pan American Health Organization/World Health Organization, 2017). Every year the Latino Medical Student Association (LMSA) from the University of South Florida (USF) Morsani College of Medicine (MCOM) travels to Jarabacoa, Dominican Republic, to provide medical care and health education to the local people. Due to the increasing prevalence and concern about the Zika virus, members of LMSA decided to assess local people's knowledge, attitudes and practices towards prevention and spread of infection. Because this virus is one of the only known infectious diseases that are transmitted both sexually and vector-borne, the survey administered attempted to ascertain how knowledge of the virus relates to sexual practices and pregnancy prevention (Paz-Bailey et al., 2017). In addition, the survey helped to determine the general fund of knowledge the public has about the Zika virus, how the people obtain information, what they are currently doing to protect themselves from virus spread, whether or not the public 
perception of the virus is accurate and what information is being provided to the general public. This information will help establish the baseline attitudes and knowledge of the Zika virus in this community with the goal of guiding future efforts toward public education and prevention of future public health threats. To date, research on the dissemination of public health information or assessment of public attitudes, knowledge and practices within the rural communities of the Dominican Republic is limited. There is some public health data on knowledge, attitudes and practices in the Dominican Republic provided by the WHO and Pan American Health Association in 2016, but it is limited in evaluating rural communities and the differentiation of non-vector transmission vs. vector transmission of Zika (Pan American Health Organization/World Health Organization, 2017; Pan American Health Organization/World Health Organization/World Vision, 2016). Currently, two independent medical mission groups from USF MCOM travel to Jarabacoa each year to provide healthcare services to the residents. By establishing baseline knowledge and practices toward Zika and its transmission, these groups will be better able to tailor education toward disease transmission, both vector borne and non-vector borne. In addition, this information could help guide future public education in rural communities of the Dominican Republic. Ultimately, the future goal is to educate the residents properly about the virus in order to decrease or minimize the spread of infection.

\section{Methods}

\subsection{Participants}

Any individual who entered our clinic who was a native, Spanish-speaking Dominican above the age of 18 and who signed a consent form to participate in the study was eligible. Individuals were excluded if they were below the age of 18 or those that did not want to participate in the study.

\subsection{Sampling Procedures}

\subsubsection{Sample Size}

Our goal was to achieve a sample size of $>100$ individuals with an average age of 30 . We estimated this based on the previous number of clinic visitors each year. Around 600 individuals visit per year, the majority being women each with 2-4 children with them. This left about 150-200 individuals over the age of 18 and we estimated around half would be willing to participate. We achieved this goal and had a total of 138 participants with an average age of 34.4 years of age.

\subsubsection{Selection}

Individuals were selected based on those who presented to our temporary medical clinics set up in different locations throughout the community of Jarabacoa. Locations were pre-determined by a LMSA representative based on the areas with the densest population and those areas with the most need for medical services. Participation was strictly voluntary. No participants received any rewards for completing survey.

\subsubsection{Survey Completion}

Individuals who entered our clinic above the age of 18 were given the option of completing the survey. If they agreed to participate, they were given a consent to read, or be read to depending on their preference. If they agreed, they were sent to a member of our research team in the clinic who would help them fill out the form. The surveys were only filled out by participants. All research documentation was managed strictly by the research team and kept in a locked room in a locked closet when not in use at clinic. No patient identifiers were collected.

\subsubsection{Measures}

This study was conducted as a cross-sectional, 14-point paper survey and was conducted during October 2016 and October 2017. Surveys were translated into Spanish and verified by a native Dominican speaker. The survey was designed using elements of the World Health Organization (2016) recommended question bank for assessing the knowledge, attitudes and practices of Zika virus in communities. However, the survey was shortened significantly compared to the WHO and tailored to answer our specific questions given the setting and time constraints of a temporary medical clinic. Questions types included i) yes/no ii) free response iii) likert scale of level of concern from 1-5 (1= no concern, $3=$ neutral, $5=$ extremely concerned $)$, iv $)$ circle all that apply. Participants were asked how they protected themselves from the virus including mosquito nets, long sleeves, repellent, condoms, getting rid of standing water or simply prayer. They were asked how they learned about the virus including family, friends, flyers, TV, news, their medical provider or billboards. Their knowledge of the virus was assessed by asking them how the virus was contracted, i.e. mosquitos, blood, sex, pregnancy. Women were specifically asked if they were pregnant or had children. Participants were also asked what form of contraception they used. Surveys were filled out with members of the research team in the temporary medical clinics. 


\subsection{Analysis}

Data was translated from paper surveys and organized into an Excel document on a secure computer on a secure network and analyzed using SPSS 22. Descriptive statistics and percentages were calculated for the following questions with both genders and years included: where they learned about zika, where they learned about zika protection, how zika is transmitted, and what they are doing to protect themselves from it. We also selected various factors (including where they learned about zika, what protection methods they are using, knowledge of zika virus transmission, birth control usage, gender, etc) and compared the level of concern for zika contraction vs whether they answered yes or no to these factors. We then compared the yes or no response for each factor with a simple t-test to determine if there were significant differences between the yes or no response. Standard error was calculated in SPSS 22 for each variable and added to the graphs. In addition, A cross tabulation was generated to calculate percentages of women using a certain type of birth control vs their level of concern for contracting the zika virus to determine if there was an association between birth control method and level of concern for contraction of the virus. We also questioned whether gender affected which prevention method people were using. Yes or no responses to various prevention practices were compared vs gender using simpe ttests in SPSS 22, and standard error was determined and added to the graphs. A composite variable was generated for knowledge about zika transmission based on how many correct choices the participant circled. A composite variable was also generated for the total number of prevention practices a participant was using. These composite variables were each separately compared to the participant's level of concern for contraction of the virus using a one-way ANOVA in SPSS 22.

\section{Results}

Data was collected during two 3-day periods in October 2016 and 2017. The total sample size was 138 combined over the two years. The result showed that the mean response age of 34.4 years old and $89.2 \%(\mathrm{~N}=124)$ of them were female.

\subsection{Statistic and Data Analysis}

For the total level of concern, on a scale of $1-5$ ( $1=$ no concern, $3=$ neutral, $5=$ extremely concerned), the average over two years was 3.52. Overall, women were more concerned than men about contracting the virus $(\mathrm{p}<.001, \mathrm{CI}$ $-2.477,-0.765$ ) (Figure 1). Of 68 respondents, $66 \%$ learned about Zika virus from the TV/news, $15 \%$ from flyers, $10 \%$ from family/friends, $6 \%$ from billboards and $7 \%$ other. $81 \%$ knew that it is contracted from mosquitoes, $5 \%$ from blood, $2 \%$ from pregnancy, and only $17 \%$ of respondents knew that it is contracted through sex. For protection, $63 \%$ eliminated standing water, $53 \%$ use mosquito nets, $41 \%$ prayed to God, $29 \%$ use mosquito repellent, $26 \%$ wear long sleeves, and only $8 \%$ used condoms. Of the places people learned about protection from Zika, $61 \%$ were from TV/news, $32 \%$ from their medical provider, $21 \%$ from flyers, $18 \%$ from family/friends, $9 \%$ from billboards and $7 \%$ from other (Table 1).

Table 1. Descriptive data for knowledge and protection against the Zika virus

\begin{tabular}{|c|c|c|c|c|c|c|c|c|}
\hline \multirow[b]{2}{*}{$\begin{array}{l}\text { Method of } \\
\text { Concern }\end{array}$} & \multirow[b]{2}{*}{ Birth Control } & \multirow[b]{2}{*}{ vs Level of } & \multicolumn{5}{|c|}{ Level of Concern } & \multirow[b]{2}{*}{$\begin{array}{l}\text { Total } \\
\text { No. } \%\end{array}$} \\
\hline & & & $\begin{array}{l}\text { No } \\
\text { concern } \\
\text { No. } \%\end{array}$ & $\begin{array}{l}\text { Some } \\
\text { concern } \\
\text { No. } \%\end{array}$ & $\begin{array}{l}\text { Moderate } \\
\text { concern } \\
\text { No. } \%\end{array}$ & $\begin{array}{l}\text { Very } \\
\text { concerned } \\
\text { No. } \%\end{array}$ & $\begin{array}{l}\text { Extremely } \\
\text { concerned } \\
\text { No. } \%\end{array}$ & \\
\hline \multirow{7}{*}{$\begin{array}{l}\mathrm{BC} \\
\text { method }\end{array}$} & Condoms & Count & $\begin{array}{ll}1 & 1.9\end{array}$ & 00.0 & $\begin{array}{ll}0 & 0.0\end{array}$ & 00.0 & $\begin{array}{ll}1 & 1.9\end{array}$ & 23.8 \\
\hline & Pills & Count & 11.9 & 11.9 & 11.9 & 11.9 & 917.0 & 1324.5 \\
\hline & Injections & Count & 00.0 & $\begin{array}{ll}0 & 0.0\end{array}$ & 11.9 & 11.9 & 11.9 & 35.7 \\
\hline & Arm implant & Count & 11.9 & 00.0 & 00.0 & $0 \quad 1.9$ & 00.0 & 11.9 \\
\hline & IUD & Count & $\begin{array}{ll}0 & 0.0\end{array}$ & $\begin{array}{ll}1 & 1.9\end{array}$ & $\begin{array}{ll}0 & 0.0\end{array}$ & $\begin{array}{ll}1 & 1.9\end{array}$ & $\begin{array}{ll}0 & 0.0\end{array}$ & 23.8 \\
\hline & Other & Count & 35.7 & 11.9 & 23.8 & 47.5 & 1018.9 & 2037.7 \\
\hline & No BC & Count & 35.7 & 11.9 & $\begin{array}{ll}1 & 1.9\end{array}$ & 00.0 & 713.2 & 1222.6 \\
\hline Total & & Count & $\begin{array}{ll}9 & 17.0\end{array}$ & 47.5 & 59.4 & 713.2 & 2852.8 & 53100 \\
\hline
\end{tabular}




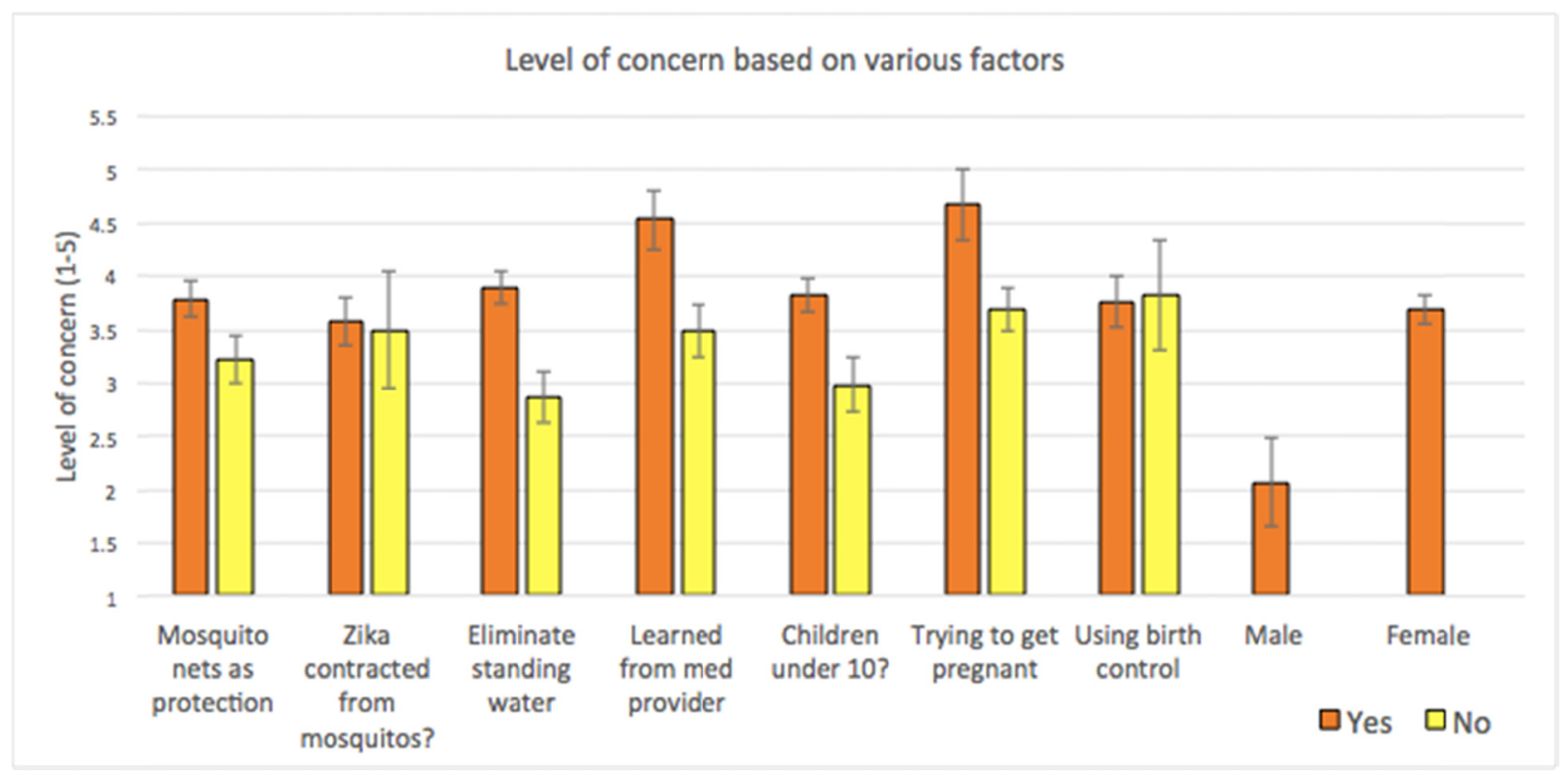

Figure 1. Level of concern based on various factors. LOC toward contracting Zika was significantly higher in people who use mosquito nets as protection $(\mathrm{p}=.047)$, people who eliminate standing water $(\mathrm{p}=.001)$, people who learned about Zika from a medical provider $(\mathrm{p}=.016)$, and those with children under the age of ten $(\mathrm{p}=.007)$

(Figure 1). No differences in LOC were found in those that know Zika is contracted from mosquitoes, those who are trying to become pregnant, or those using birth control. Women were more concerned than men $(p=.002)$

Composite scores were generated for prevention practice as well as knowledge of Zika and were compared against the level of concern for infection. For prevention practice, the total number of prevention practices that people used were summed, and then compared against level of concern. Then, a one-way ANOVA was used to compare the mean number of prevention practices vs the level of concern. There was no statistically significant difference between these means, but the $p$-value approached significance $(\mathrm{p}=.161)$ and there was a general trend of increased concern when the number of prevention practices increased (Figure 6). The same analysis was done for Zika knowledge. The number of correct methods of transmission that people circled were summed, and compared against the level of concern. There was no statistically significant difference between these means based on one-way ANOVA ( $\mathrm{p}=0.524$ ) (Figure 6).

As stated previously, gender significantly contributed to overall level of concern ( $<<.001, \mathrm{CI}-2.477,-0.765)$. However, when compared against different prevention practices, no differences were found in level of concern. Gender did not significantly contribute to whether or not someone used mosquito nets, eliminated standing water, used mosquito repellent, wore long sleeves, used condoms or prayed to God (Figure 5).

There were a few factors that contributed significantly to overall level of concern. Level of concern for virus contraction was significantly higher in those that use mosquito nets as protection $(p=0.047)$, eliminate standing water $(\mathrm{p}=0.001)$, people who learned about Zika from a medical provider $(\mathrm{p}=0.016)$, and those with children under the age of $10(\mathrm{p}=0.007)$ (Figure 1).

Questions about birth control methods were asked of the women that filled out the surveys. Of 53 respondents that answered this portion of the survey, $23 \%$ of women surveyed used no form of birth control, $38 \%$ used "other" forms, $25 \%$ of women use oral contraceptive pills, $4 \%$ use condoms, $6 \%$ use an injection, $2 \%$ use an arm implant, and $4 \%$ use an IUD (Table 2). Interestingly, 9 of 13 women using pills were "extremely concerned," and 7 of 12 women using no birth control were "extremely concerned." The sample size was not large enough to draw any significant conclusions from the data collected, but the results are intriguing nonetheless. Of the women trying to get pregnant, the average level of concern was 4.67/5. Amongst these women, only one was using mosquito nets as protection and none had knowledge that Zika could be transmitted through sex or learned about virus protection from their medical provider. 
Table 2. Level of concern vs contraception method

\begin{tabular}{|c|c|c|c|}
\hline & & Sum & Percent (\%) \\
\hline \multirow{6}{*}{$\begin{array}{l}\text { Where they learned } \\
\text { about Zika }\end{array}$} & TV/News & $45 / 68$ & 66.0 \\
\hline & Family/friends & $7 / 68$ & 10.0 \\
\hline & Flyers & $10 / 68$ & 15.0 \\
\hline & Medical Provider & $16 / 68$ & 24.0 \\
\hline & Billboards & $4 / 68$ & 60.0 \\
\hline & Other & $5 / 68$ & 70.0 \\
\hline \multirow{6}{*}{$\begin{array}{l}\text { Where they learned } \\
\text { about Zika protection }\end{array}$} & Family/friends & $10 / 57$ & 18.0 \\
\hline & Flyers & $12 / 57$ & 21.0 \\
\hline & Medical Provider & $18 / 57$ & 32.0 \\
\hline & TV/News & $35 / 57$ & 61.0 \\
\hline & Billboards & $5 / 57$ & 9.0 \\
\hline & Other & $4 / 57$ & 7.0 \\
\hline \multirow{5}{*}{ How Zika is contracted? } & Mosquitos & $52 / 64$ & 81.0 \\
\hline & Sex & $11 / 64$ & 17.0 \\
\hline & Blood & $3 / 64$ & 5.0 \\
\hline & Pregnancy & $1 / 64$ & 2.0 \\
\hline & Don't know & $11 / 64$ & 17.0 \\
\hline \multirow{6}{*}{ Protection } & Mosquito nets & $73 / 136$ & 54.0 \\
\hline & Long sleeves & $36 / 136$ & 26.0 \\
\hline & Eliminate standing water & $86 / 136$ & 63.0 \\
\hline & Mosquito repellent & $40 / 136$ & 29.0 \\
\hline & Condoms & $11 / 136$ & 8.0 \\
\hline & Pray to God & $56 / 136$ & 41.0 \\
\hline
\end{tabular}

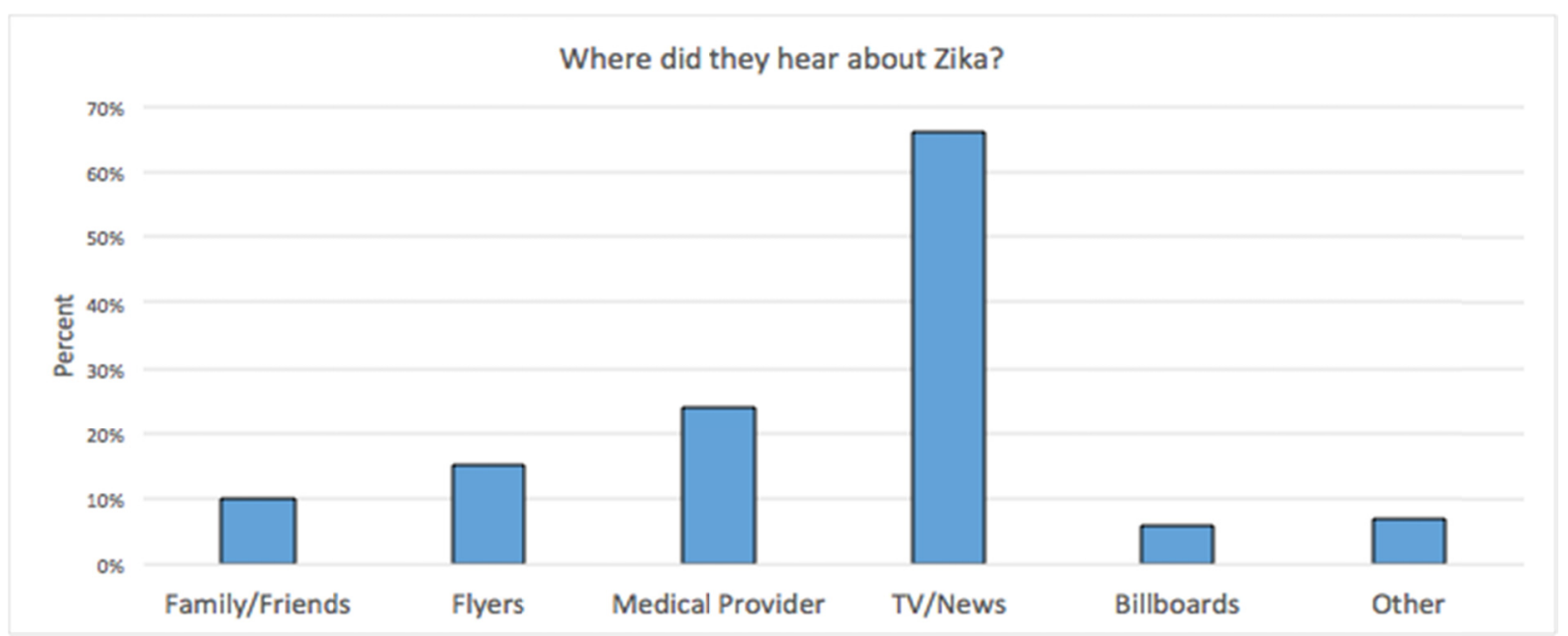

Figure 2. Percent of respondents learned about Zika from various sources. $66 \%$ learned about it from TV/news, $24 \%$ from a medical provider, $15 \%$ from flyers, $10 \%$ from family/ friends, $6 \%$ from billboards and $7 \%$ other 


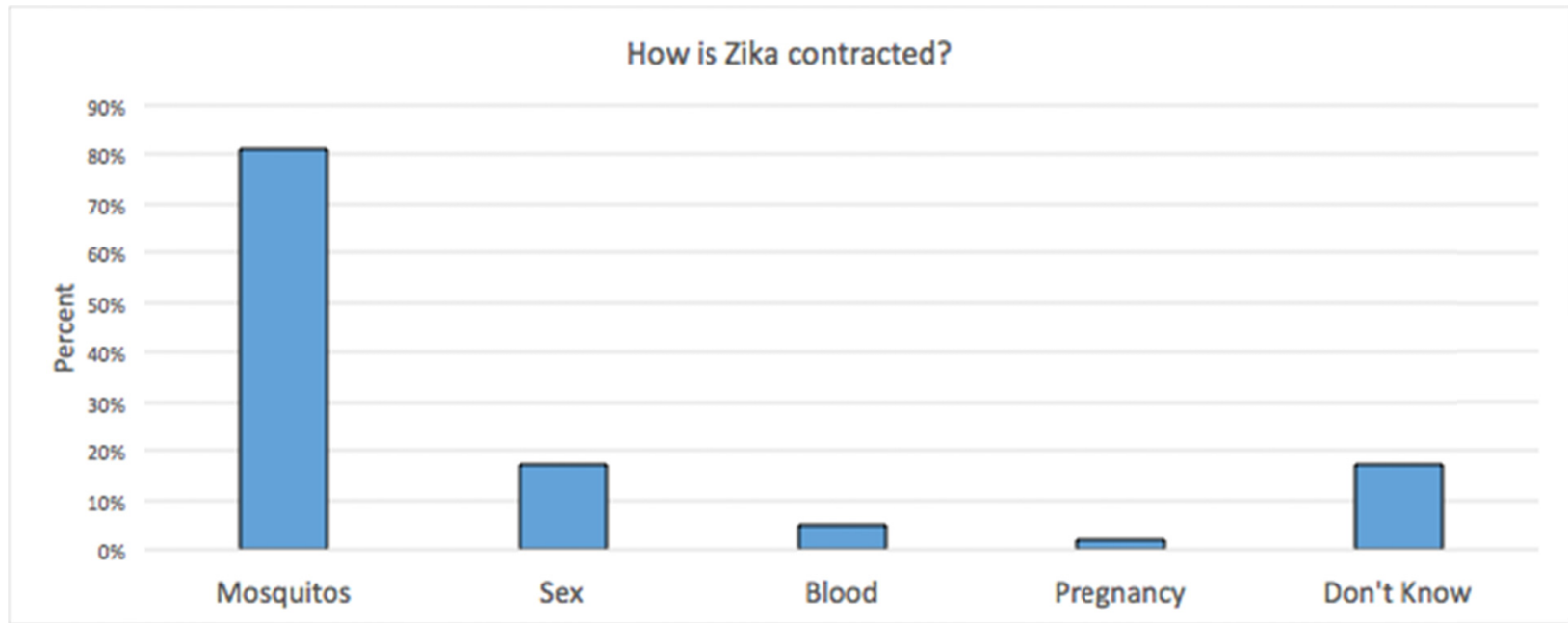

Figure 3. Percent of respondents who know the various ways Zika can be transmitted. $81 \%$ know it is transmitted through mosquitoes, $17 \%$ through sex, $5 \%$ through blood, $2 \%$ through pregnancy and $17 \%$ do not know how it is transmitted

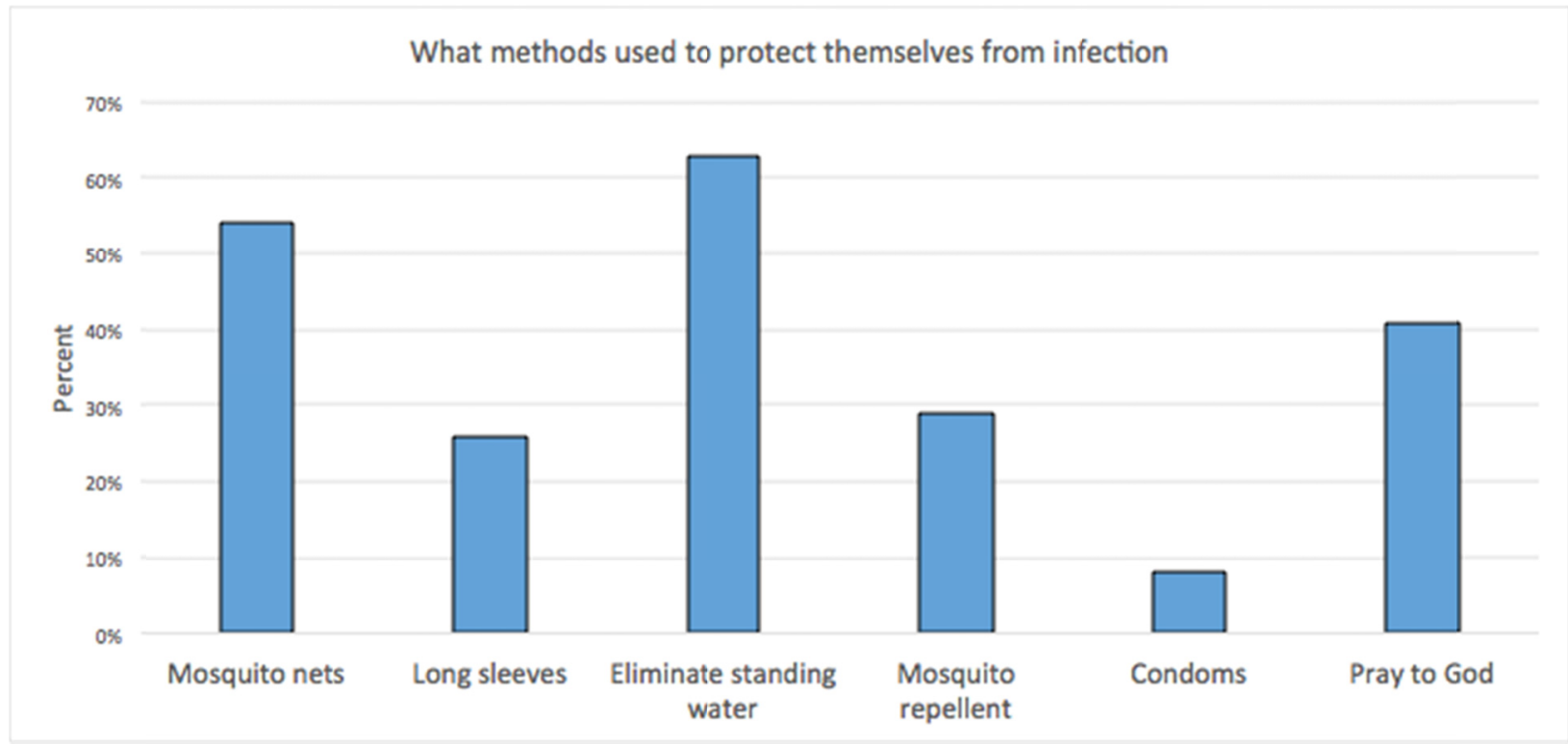

Figure 4. Percent of respondents using various prevention practices. $63 \%$ eliminate standing water, $54 \%$ use mosquito nets, $29 \%$ wear long sleeves, $8 \%$ use condoms and $41 \%$ pray to God 


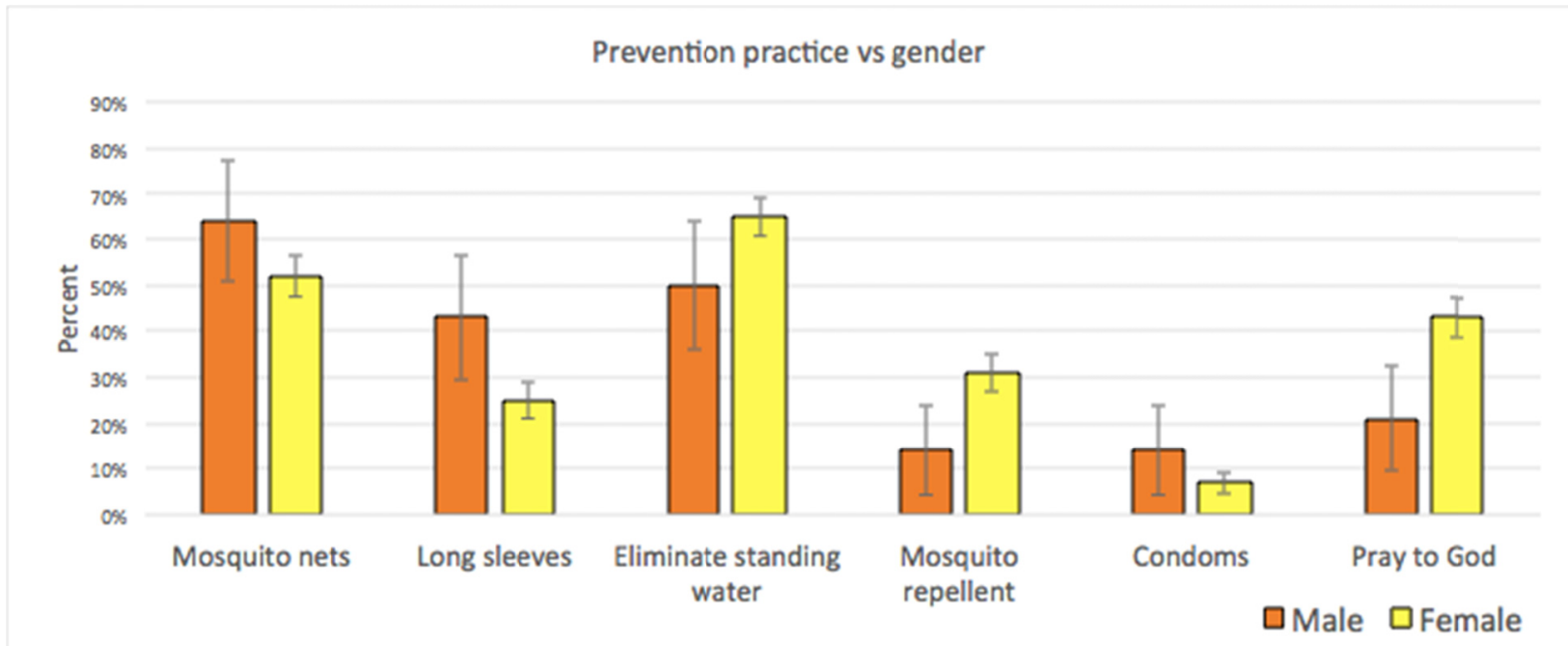

Figure 5. Prevention practice differences between male and female. No significant differences were found between the fenders with regards to using mosquito nets, wearing long sleeves, eliminating standing water, using mosquito repellent, using condoms or praying to God

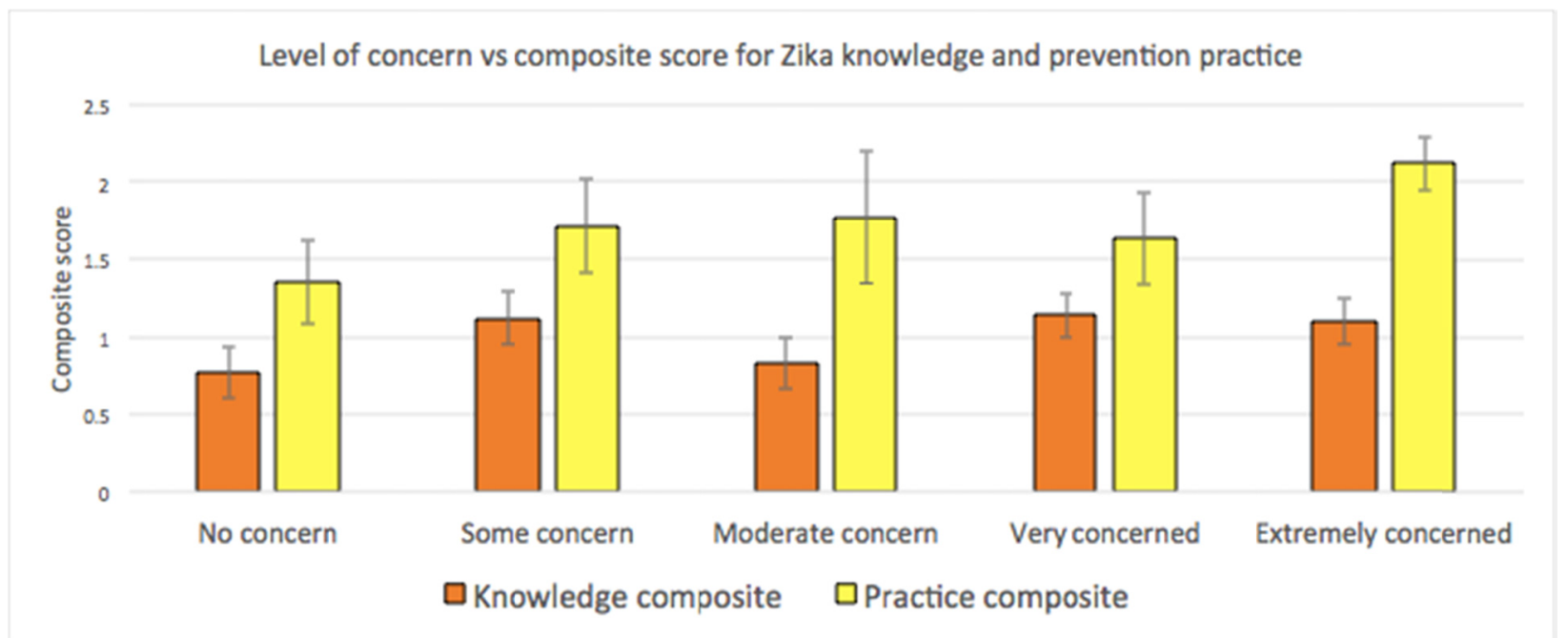

Figure 6. LOC vs. composite scores for Zika knowledge and prevention practice. No differences were found in composite knowledge scores vs. LOC based on one-way ANOVA $(\mathrm{p}=.524)$. Composite prevention practice was approaching significance based on one-way ANOVA (p-.161) with a general trend of increasing composite score with higher LOC

\section{Discussion}

The goal of our study was to ascertain the current knowledge, attitudes and practices in regards to the Zika virus and its vector borne and non-vector borne transmission in the rural community of Jarabacoa in the Dominican Republic. Our findings showed that $66 \%$ of people learned about the Zika virus from the TV/news suggesting that the number one source of public health knowledge for this rural community was TV. This is in agreement with a study done in Iquitos, Peru, where it was found that the population also gained most of their Zika knowledge from television, flyers and radio (Weldon, et al., 2018). Overall, $71 \%$ of respondents knew that Zika could be transmitted by mosquito bite. However, only $17 \%$ knew it could be sexually transmitted and only 5\% were aware it could be spread by blood. This was found to be in agreement with a PAHO/WHO/World Vision study in the Dominican Republic in 2016 which suggested only 4\% of the population knew that Zika could be sexually transmitted (Pan American Health Organization/World Health Organization/World Vision, 2016). This is concerning when studies such as that by Coelho et al. (2016) demonstrated that women in Rio de Janeiro had $90 \%$ more cases of Zika because of sexual transmission. Zika appears to have an interesting propensity for 
vertical transmission, unlike other members of the flavivirus genus like dengue, west nile, yellow fever, and St. Louis encephalitis (Ciota, Bialosuknia, Ehrbar \& Kramer, 2017). These other viruses can undergo vertical transmission, however, they are much less successful than Zika (Ciota, Bialosuknia, Ehrbar \& Kramer, 2017). In particular, Zika seems to persist in serum, urine and semen the longest but is unlikely to be transmitted from vaginal secretions or saliva (Paz-Bailey et al., 2017). Therefore, one of the more important modes of protection against Zika appears to be from the use of condoms or abstinence from sexual activity. However, our study showed that only $7 \%$ of participants used condoms. It is difficult to say if this low number is due to cultural beliefs or other factors entirely. It is unclear how many cases of Zika in the Dominican Republic are from sexual transmission, however, the Coelho et al. (2016) study suggests it is likely contributing to overall Zika infections.

A review of the literature suggests that there is a gap in public knowledge when it comes to information about the transmission of Zika virus. The study by PAHO/WHO/World Vision in the Dominican Republic (2016) further showed that around $57 \%$ of the population felt that both local and national organizations have not done enough to protect the population from Zika. The lack of proper public health education on the Zika virus becomes even more evident when compared with other Caribbean public health campaigns such as that in Martinique. Delet, Cabie, Merle, Volumenie \& Monthieux (2018) showed that around 44\% of the population was aware that Zika was transmitted sexually and $97.3 \% \mathrm{knew}$ it was transmitted by mosquitoes. This increased knowledge was due to a public health campaign to educate patients in the OB/GYN setting and through media outlets such as television, newspapers and the internet. Interestingly, women in this study seemed to utilize more protective measures for the vector borne aspect of transmission such as sprays, removal of standing water and wearing long sleeves. However, similar to our study, only $7 \%$ of respondents used condoms for protection despite the increased knowledge of sexual transmission (44\% vs. $17 \%$ in our study) (Delet, Cabie, Merle, Volumenie \& Monthieux, 2018). This possibly suggests a similarity in cultural beliefs against the use of condoms or perhaps lack of concern of sexual transmission of Zika despite knowledge of the possibility. Interestingly, another study in Malaysia showed residents had a lack of concern about sexual transmission of Zika (Arief et al., 2017). With this in mind, the importance of future efforts at encouraging adherence to CDC guidelines for prevention of sexual transmission of Zika cannot be understated. Casapulla, Aidoo-Frimpong, Basta, and Grijalva (2018) suggested that in Ecuador, in addition to catholicism, another potential barrier to condom use could be due to cost. $18 \%$ of their participants stated cost as a barrier to obtaining condoms. This is a possibility in the Dominican Republic where about $30 \%$ of the population lives below the poverty line (Central Intelligence Agency, 2015). One study attempted to associate male concern for demonstrating masculinity with various sexual risk factors in the Dominican Republic, such as inconsistent condom use, using the gender roles conflict/stress (GRC/S) scale. It was an adapted seventeen question study with various questions addressing what men view as masculine. They found that a higher GRC/S scale was associated with less frequent condom usage, suggesting that males perceived consistent condom usage as less masculine (Fleming et al., 2018). The case study published by Brooks et al. (2018) identified a woman infected with Zika virus by RT-PCR who had had condomless sexual intercourse with a man who displayed no symptoms. The woman had no history of travel, but the man had traveled to the Dominican Republic approximately two weeks prior to their encounter. The spread of Zika virus from asymptomatic males through condomless sexual intercourse to pregnant women early in pregnancy who may not know they are pregnant is a very real and disturbing possibility for both the mother and the fetus. This further highlights the importance for consistent condom use as well as increased public awareness in the Dominican Republic about Zika virus transmission methods. However, future research will have to focus on barriers to obtaining and using condoms in the rural populations of the Dominican Republic.

A special population to consider are those attempting to become pregnant where consistent condom usage is not feasible. The CDC currently recommends abstaining from sexual contact or using condoms for three months after the development of symptoms suspicious for Zika virus infection. In addition, they recommend abstaining from sexual intercourse during pregnancy, or consistent condom use (CDC, 2018). It is not practical to test the serum of all individuals before attempting pregnancy, so these guidelines should be followed. For future LMSA trips to the Dominican Republic, there should be discussions with women who are trying to conceive, and to provide recommendations to them should they decide to have a planned pregnancy.

Another interesting finding in our study was related to the composite scores of knowledge of Zika transmission and prevention practices. Knowledge of Zika transmission methods did not seem to influence the level of concern for virus contraction. We hypothesized that increased knowledge of transmission methods would thus increase the level of concern for Zika contraction, but this did not seem to be the case in our study. This could be because the number of people that circled multiple correct transmission methods was very low compared to how many chose just one (usually mosquitoes), resulting in an inadequate response for statistical significance. The number of prevention practices used slightly increased as level of concern for contraction increased, but was not statistically significant. However, it is an interesting pattern and one that should be followed up on because it seems that as level of concern for virus contraction increases, the number of prevention practices may also 
increase. But from our data, we cannot prove this as the results were not statistically significant.

Unfortunately, our sample size for these questions was not large enough to draw any definitive conclusions, however it does suggest need for reevaluation of public health education and further research on this topic. The Dominican Republic would most likely benefit from more accurate and complete dissemination of information about the Zika virus from both health care providers and their primary source of information, television. Thus, improved health literacy can be accomplished by providing better information to television networks and through social media campaigns. It should be noted that Zika knowledge is perhaps associated with socioeconomic status or level of education. In one study in Brazil, it was found that education level was positively correlated with knowledge of Zika transmission and with current Zika virus prevention practice such as eliminating standing water, using mosquito nets and repellent (Carvalho et al., 2017). In our study population, level of education is generally low and thus likely contributing to the lack of knowledge about the various transmission methods. Even in well-educated countries such as the United States, Zika knowledge is lagging. Of 200 survey respondents in one study in New York City, only $46 \%$ knew of the risk of disabilities to babies, and only $25 \%$ knew about sexual transmission (Samuel et al., 2018). This speaks to the difficulty of disseminating accurate public health information, even in highly educated countries. However, knowledge about Zika was relatively limited at the beginning of the most recent outbreaks and is still being actively researched. As a result, public health information and education is most likely lagging behind as new information is becoming available. In addition, the relative success of the Martinique public health campaigns may or may not be comparable to that of the Dominican Republic as it is a part of the European Union and generally a wealthier nation. Regardless, communicating the new and accurate findings about Zika to the public will be important for the Dominican Republic in the future and also for the LMSA group to emphasize patient education about virus transmission on subsequent mission trips.

Further research needs to be done on the non-vector transmission of Zika in order to properly drive public education. Many avenues of virus transmission such as breast milk, seminal fluid, saliva, urine, amniotic fluid and blood are still being studied (Grischott, Puhan, Hatz \& Schlagenhauf, 2016; Paz-Bailey et al., 2017). In addition, research looking into dissemination of public health information between rural and urban centers would be useful to find any discrepancies in knowledge between these populations. Delet et al. showed that about $64 \%$ of respondents wished more information was available on the internet and social media (Delet et al., 2018). Future research should be done to assess whether the internet would be a viable avenue of public health dissemination in the Dominican Republic. In addition, future studies would benefit from having more male participants and more focus on pregnancy, pregnancy intentions and contraception use as well as how these factors relate to prevention of Zika transmission.

\section{Conclusions}

This study revealed that women in Jarabacoa, Dominican Republic, were more concerned about Zika virus than men, and knowledge about the virus was limited. In general, people are protecting themselves against vector borne transmission but not non-vector borne modes of transmission. This is possibly due to the fact that people received most of their knowledge from the TV/news and medical providers who provided limited information, neglecting the sexual transmission aspect. In addition, due to the fact that research is still being actively done on the Zika virus, public health information and education has most likely not adequately caught up to the most recent information. Future medical mission trips should focus on better overall Zika virus education and information on personal protection measures such as barrier contraception. Limitations of the study include the small sample size $(\mathrm{N}=138)$. In addition, the study was only conducted in one rural population of the Dominican Republic and only tested subjects that came to clinic. In addition, the study had a majority of women. Future research studies are needed with more male participants, comparing dissemination of information in rural vs. urban communities, looking at pregnancy intention's affect on Zika knowledge and contraception use, and focus on social media's effect on public health education.

\section{Acknowledgements}

The authors would like to extend the warmest gratitude to the communities of Jarabacoa for allowing LMSA to continue to administer healthcare to their community and in conducting this research to help improve overall quality of their public health.

\section{Competing Interest Statement}

None of the contributing authors have any conflicts of interest to disclose.

\section{References}

Arief, M., Hassali, M. A., Saleem, F., Khan, M. U., Ahmad, A., Bhagavathulha, A. S., \& Jamshed, S. (2017). A Cross-sectional Survey on the Knowledge and Attitudes towards Zika Virus and its Prevention among 
Residents of Selangor, Malaysia. Journal of Pharmacy Practice and Community Medicine, 3(2), 81-89. doi:10.5530/jppcm.2017.2.20.

Brooks, R. B., Carlos, M. P., Myers, R. A., White, M. G., Bobo-Lenoci, T., Aplan, D., ... Feldman, K. A. (2016) Likely transmission of Zika virus from a man with no symptoms of infection - Maryland, 2016. MMWR. Morbidity and Mortality Weekly Report. 2;65(34), 915-6. https://doi.org/10.15585/mmwr.mm6534e2.

Cao-Lormeau, V. M., Blake, A., Mons, S., Lastere, S., Roche, C., Vanhomwegen, J., ... Ghawché, F. (2016). Guillain-Barré Syndrome outbreak associated with Zika virus infection in French Polynesia: a case-control study. Lancet, 387(10027), 1531-1539. https://doi.org/10.1016/S0140-6736(16)00562-6

Carvalho, J. R., Oliveria, V. H., \& Quintana-Domeque, C. (2017). Zika Virus Prevalence, Correlates and Preventive Behaviors: New Evidence from Survey Data. IZA Discussion Paper No. 10591. Available at SSRN: https://ssrn.com/abstract $=2931288$

Casapulla, S. L., Aidoo-Frimpong, G., Basta, T. B., \& Grijalva, M. J. (2018). Zika virus knowledge and attitudes in Ecuador. AIMS Public Health, 5(1), 49-63. Https://doi.org/10.3934/publichealth.2018.1.49

Centers for Disease Control and Prevention. (2018). Zika and Pregnancy. Retrieved October 13, 2018, from https://www.cdc.gov/pregnancy/zika/women-and-their-partners.html

Central Intelligence Agency. (2015). The World Factbook- Dominican Republic. Retrieved October 10, 2018, from https://www.cia.gov/library/publications/the-world-factbook/geos/dr.html

Chouin-Carneiro, T., Vega-Rua, A., Vazeille, M., Yebakima, A., Girod, R., Goindin, D., ... Failloux, A. B. (2016). Differential Susceptibilities of Aedes aegypti and Aedes albopictus from the Americas to Zika Virus. PLos Negl Trop Dis, 10(3), e0004543. https://doi.org/10.1371/journal.pntd.0004543

Ciota, A. T., Bialosuknia, S. M., Ehrbar, D. J., \& Kramer, L. D. (2017). Vertical Transmission of Zika Virus by Aedes aegypti and Ae. albopictus Mosquitoes. Emerg Infect Dis, 23(5), 880-882. https://doi.org/10.3201/eid2305.162041

Coelho, F. C., Durovni, B., Saraceni, V., Lemos, C., Codeco, C. T., Camargo, S., ... Armstrong, M. (2016). Higher incidence of Zika in adult women than adult men in Rio de Janeiro suggests a significant contribution of sexual transmission from men to women. Int $J$ Infect Dis, 51, 128-132. https://doi.org/10.1016/j.ijid.2016.08.023

Delet, J., Cabie, A., Merle, S., Volumenie, J. L., \& Monthieux, A. (2018). Knowledge, attitudes and practices of pregnant women in Martinique in the immediate aftermath of the Zika virus outbreak. Eur J Obstet Gynecol Reprod Biol, 222, 70-74. https://doi.org/10.1016/j.ejogrb.2018.01.010

D’Ortenzio, E., Matheron, S., Yazdanpanah, Y., de Lamballerie, X., Hubert, B., Piorkowski, G., ... LeparcGoffart, I. (2016). Evidence of Sexual Transmission of Zika Virus. N Engl J Med; 374:2195-2198. https://doi.org/10.1056/NEJMc1604449

Fleming, P. J., Barrington, C., Powell, W., Gottert, A., Lerebours, L., Donastorg, Y., \& Brito, M. O. (2018). The association of men's concern about demonstrating masculine characteristics and their sexual risk behaviors: Findings from the Dominican Republic. Archives of Sexual Behavior, 47(2), 507-514. https://doi.org/10.1007/s10508-016-0880-6

Goncé, A., Martínez, M. J., Marbán-Castro, E., Saco, A., Soler, A., Alvarez-Mora, M. I., ... Bardají, A. (2018). Spontaneous abortion associated with Zika virus infection and persistent viremia. Emerging Infectious Diseases, 24(5), 933-935. https://doi.org/10.3201/eid2405.171479

Grischott, F., Puhan, M., Hatz, C., \& Schlagenhauf, P. (2016). Non-vector-borne transmission of Zika virus: a systematic review. Travel Med Infect Dis, 14(4), 313-30. https://doi.org/10.1016/j.tmaid.2016.07.002

Mlakar, J., Korva, M., Tul, N., Popovic, M., Poljsak-Prijatelj, M., Mraz, J., ... Zupanc, T. A. (2016). Zika Virus Associated with Microcephaly. N Engl J Med; 374:951-958. https://doi.org/10.1056/NEJMoa1600651.

Pan American Health Organization/World Health Organization. (2017). Zika-Epidemiological Report Dominican Republic. $\quad$ Retrieved June 6, 2018, from http://www.paho.org/hq/index.php?option=com_docman\&task=doc_view\&gid=35103\&Itemid=270\&lang= en

Pan American Health Organization/World Health Organization/World Vision. (2016). Emergencia ZIKV: Resultados del proceso de consulta conocimientos, actitudes y prácticas sobre ZIKV informe de pais: República Dominicana. Retrieved June 6, 2018, from https://www.paho.org/hq/index.php?option=com_docman\&task=doc_view\&Itemid=270\&gid=38065\&lang $=\mathrm{en}$ 
Paz-Bailey, G., Rosenberg, E. S., Doyle, K., Munoz-Jordan, J., Santiago, J., Santiago, G. A, ... Sharp, T. M. (2017). Persistence of Zika virus in body fluids - preliminary report. N Engl J Med. (Epub ahead of print). https://doi.org/10.1056/NEJMoa1613108. https://doi.org/10.1056/NEJMoa1613108

Rasmussen S. A., Jamieson D. J., Honein M. A., \& Petersen, L. R. (2016). Zika Virus and Birth DefectsReviewing the Evidence for Causality. N Engl J Med, 374(20), 1981-7. https://doi.org/10.1056/NEJMsr1604338

Samuel, G., DiBartolo-Cordovano, R., Taj, I., Merriam, A., Lopez, J. M., Torres, C., ... Thakur, K. T. (2018). A survey of the knowledge, attitudes and practices on Zika virus in New York City. BMC Public Health, 18(1), 98. https://doi.org/10.1186/s12889-017-4991-3

Weldon, C. T., Riley-Powell, A. R., Aguerre, I. M., Celis Nacimento, R. A., Morrison, A. C., Oberhelman, R. A., \& Paz-Soldan, V. A. (2018). "Zika is everywhere": A qualitative exploration of knowledge, attitudes and practices towards Zika virus among women of reproductive age in Iquitos, Peru. PLoS Neglected Tropical Diseases, 12(8), e0006708. https://doi.org/10.1371/journal.pntd.0006708

World Health Organization. (2016). Knowledge, Attitudes and Practices surveys Zika virus disease and potential complications resource pack. Retrieved from http://www.who.int/csr/resources/publications/zika/kapsurveys/en/

\section{Copyrights}

Copyright for this article is retained by the author(s), with first publication rights granted to the journal.

This is an open-access article distributed under the terms and conditions of the Creative Commons Attribution license (http://creativecommons.org/licenses/by/4.0/). 